\title{
Considerations and beliefs in tooth donation to research in Jordan
}

This article was published in the following Dove Press journal: Clinical, Cosmetic and Investigational Dentistry

\author{
Noor Al Mortadi' \\ Omar F Khabour ${ }^{2}$ \\ Karem H Alzoubi ${ }^{3}$ \\ 'Department of Applied Dental \\ Sciences, Faculty of Applied Medical \\ Sciences, Jordan University of \\ Science and Technology, Irbid, Jordan; \\ ${ }^{2}$ Department of Applied Medical \\ Sciences, Faculty of Applied Medical \\ Sciences, Jordan University of \\ Science and Technology, Irbid, Jordan; \\ ${ }^{3}$ Department of Clinical Pharmacy, \\ Faculty of Pharmacy, Jordan University \\ of Science and Technology, Irbid, \\ Jordan
}

Correspondence: Noor Al Mortadi Department of Applied Dental Sciences, Faculty of Applied Medical Sciences, Jordan University of Science and Technology, PO Box 3030, Irbid 221 I0, Jordan

Tel +96227201000

Fax +96227201073

Email naalmortadi@just.edu.jo
Background: Research that involves dental pulp stem cells (DPSCs) is growing rapidly. DPSCs can be used for the treatment of craniofacial bone abnormalities and tooth repair. The procedure requires a donation of sound teeth, which might be associated with ethical and moral issues. The purpose of this study was to understand the attitudes and awareness of patients with respect to the donation of their teeth to research.

Patients and methods: This study involved 500 patients recruited from Dental Care and Dental Teaching Center in Irbid during May 2017-July 2017.

Results: A well-structured questionnaire was administered and prepared using Google forms and filled out using a tablet device. The majority of patients $(62.8 \%)$ were willing to donate their teeth to research with significant association with educational level. Half of the patients considered that the donated tooth belongs to them even after extraction, whereas $19 \%$ believed that the researcher owns it after donation. Almost half $(53.6 \%)$ of the participants wished to be informed about the type of scientific research that will be carried out on their teeth. The majority $(66.5 \%)$ preferred to sign a consent document on tooth donation to research during the consultation visit before extraction. Finally, about $61 \%$ were worried that their tooth might be extracted for research purposes rather than medical purposes.

Conclusion: A good fraction of Jordanian is willing to donate their teeth to research. Educational programs are demanded to enhance the awareness and attitudes of patients on the ownership of extracted teeth, consent process, and donation of teeth.

Keywords: stem cells, attitude toward ethical concerns, medical ethics, knowledge of ethical concerns, patient right, tooth donation, consent form

\section{Introduction}

The science of stem cells and their clinical use in regenerative medicine and dentistry have developed significantly over the past decade. ${ }^{1,2}$ Stem cells have the potential to repair damaged teeth, tissue regeneration of dentin, and periodontal ligament, inducing bone regeneration and treating neural injury. ${ }^{3}$ Teeth can provide a good source of stem cells that can grow rapidly. To date, in most countries, a tooth extracted in the context of a treatment plan corresponds to clinical waste, and, if used for research, it is considered a biological sample. ${ }^{4}$

Dental stem cells from dental pulp can be divided into mesenchymal dental stem cells (MDSCs) and epithelial dental stem cells. ${ }^{5}$ MDSCs can be collected from human baby teeth, ${ }^{5}$ or the extracted adult teeth, ${ }^{4}$ periodontal ligament stem cells, ${ }^{6}$ and dental follicle stem cells from human third molars. ${ }^{7,8}$ These cells have been shown parallel, although not identical in properties, to those of bone marrow mesenchymal stem cells. ${ }^{9}$ 
International guidance for conducting research involving human subjects was made explicit in the World Medical Association's Declaration of Helsinki in 1964. In addition, in January 2014, Jordan established a regulation, which was the first in the Arab and Islamic region to control research and therapy of human embryonic stem cells. ${ }^{10}$ It highlights the appreciation that Jordan has for the prospective of stem cell therapy and provides a structure for other countries in the region to follow. The law specifically limits researches or therapies to government and publicly funded institutions, which have higher levels of transparency and controlled by the health ministry and a specialized committee. ${ }^{10}$

Decision on using stem cells in Islamic countries such as Jordan should be based on advantages and limitations. From Islamic view, development and scientific researches are allowed if they benefit society as long as the least amount of harm to subjects is affected. ${ }^{11}$ The member of the health care team should offer two consents to the patient: one for tooth extraction and another for tooth donation to research. Informed consent for donation is ethically required as a means of demonstrating respect for donor's autonomy and protecting donor's safety. Informed consent has become a standard prerequisite to researches involving human subjects. ${ }^{12}$ Participants must sign the informed consent before being recruited into a study. Further to meet the institutional review board (IRB)'s guidelines and legal obligations, informed consent is essential for a wide variety of ethical reasons. For example, providing enough information in the consent form such as intended use, place of storage, and possible sample sharing will provide more transparency and is expected to enhance the trust between researchers and donors.

This study was carried out to understand the attitudes and awareness of patients with respect to donation of teeth to be extracted. It also concerned with understanding the ownership of the donated teeth and patients' expectations with respect to the information provided to sign informed consent. The study was conducted on Jordanian population as an example of the Arabic population. Donation of teeth for research is an emerging issue that concerns both researchers and participants worldwide.

\section{Patients and methods}

The study involved 500 patients recruited from the Dental Care and Dental Teaching Center in Irbid at Jordan University of Science and Technology (JUST) between May 2017 and July 2017. The center provides services for both adult and children patients. The protocol for conducting this study was approved by the IRB of JUST. The researcher invited the patients to participate in the study during their waiting time for the dental appointment and filled out the questionnaire.

A well-structured questionnaire was administered and prepared using Google forms and filled out using a tablet device. The participants were selected conveniently based on those present in the waiting room.

The questionnaire consisted of 20 closed-ended questions, including demographic profiles and questions in line with the study objectives. Part of the questions aimed to explore patients' awareness about the ethical considerations involved in obtaining the consent from the patients so that their extracted teeth can be used for research. In addition, the questionnaire investigated patients' attitudes toward donation, ownership of the extracted tooth, and beliefs of patients in giving their teeth for research purposes. Demographic variables included age, gender, place of living, highest academic levels, and income. The questionnaire was validated by pilot testing on 20 participants. It is worth to mention that the questionnaire asked questions about teeth donation for research in general and did not specify a group of teeth (ie, deciduous, permanent, and wisdom).

The patients approached were 714 with a response rate of $70 \%$. Recruitment was continued until the target number of 500 participants was reached. Inclusion criteria included the following: being an adult and willing to sign informed consent.

The data were coded using the SPSS, version 21.0 (IBM Corporation, Armonk, NY, USA), entry program. The data were summarized using frequency tables and mean and SD for continuous variables. Frequency and contingency tables were used for categorical data. Chi-squared test was used for the analysis of association between willingness to donate their teeth to research and various demographic variables of the sample.

\section{Results}

Participants $(n=500), 71 \%$ females and 29\% males, were administered the study's questionnaire. Approximately twothirds of the participants live in Irbid, which is nearby the Dental Health Center, while the rest live in the neighboring villages. The majority of participants $(87.4 \%)$ earn less than US $\$ 1,000$ as monthly income. However, the percentage of those who earn US\$1,000-US\$2,000 was $14.4 \%$ and for those who earn more than US $\$ 2,000$ was $6.4 \%$. About $60 \%$ of the participants were young adults ( $<30$ years old), and about two-thirds hold a bachelor degree. Approximately the number of health-insured participants was equal to the number of those who were not health insured. Table 1 summarizes the demographic characteristics of the study sample.

Table 2 summarizes that the majority of patients $(62.8 \%)$ were willing to donate their teeth to research, while the 
remaining prefer to keep the donated tooth with them $(6.2 \%)$ or to throw it away (35\%). Half of the participants believed that the donated tooth still belongs to them, whereas $19 \%$ believed that the tooth belongs to the researcher.

Table 3 summarizes that a considerable number of participants $(17.4 \%)$ refused to donate their teeth to research. About $61.9 \%$ of patients agreed to donate their teeth to stem cell research even though only $30.2 \%$ described their knowledge in stem cells as "excellent". Approximately two-thirds of participants $(63 \%)$ never participated in any previous research.

Almost a half $(53.6 \%)$ of the participants wished to be informed about the type of scientific research that will be carried out on their teeth after donation. In addition, $42.6 \%$ $(n=213)$ were willing to sign consent forms to donate their teeth to research. Of those who were willing and answered "yes", the majority (66.5\%) preferred to sign the consent form at the consultation visit before extraction. However,

Table I Demographic characteristics of the study participants

\begin{tabular}{|l|l|}
\hline Variable & $\mathbf{n}(\%)$ \\
\hline Gender & \\
Male & $144(28.8)$ \\
Female & $356(71.2)$ \\
\hline Place of living & \\
City & 31 I (62.2) \\
Village & $189(37.8)$ \\
\hline Educational level & \\
Less than high school & $32(6.4)$ \\
High school & $77(15.4)$ \\
Diploma & $34(6.8)$ \\
BSc & $325(65.0)$ \\
Postgraduate & $28(5.6)$ \\
\hline Monthly income (US\$) & \\
Less than $\$ 1,000$ & $395(79.0)$ \\
$\$ 1,000-\$ 2,000$ & $77(15.4)$ \\
More than $\$ 2,000$ & $28(5.6)$ \\
\hline Medical insurance for tooth extraction & \\
Yes & $303(50.6)$ \\
No & $247(49.4)$ \\
\hline
\end{tabular}

$20.2 \%$ preferred to sign the consent form at surgery visit after extraction and $13.2 \%$ agreed to sign at the surgery appointment before extraction. Most participants (60.8\%) cared about the research result. Telephone calls were the preferred communication method among participants for informing them about the research result applied on their donated teeth

Table 4 summarizes that $61.4 \%$ of participants were worried if the surgeon did the tooth extraction for them for research purposes rather than medical purposes. Of the participants, $77.6 \%$ preferred the surgeon/dentist to be the person who asks them if they agree to donate the extracted tooth to research, while $19.4 \%$ preferred a member of the research team to do that.

When the possible association between willingness to donate extracted tooth for research and various demographic variables of the study sample was examined, the level of education showed a significant association $(P=0.006)$; participants with BSc or postgraduate degrees were more likely to accept donation of tooth to research. Other demographic variables, including age, gender, income, and place of living, were not significant (Table 5).

\section{Discussion}

The study showed that the majority of the participants (62.8\%) preferred to donate their teeth to research after extraction. This was associated with educational level as participants with BSc or postgraduate degrees were more likely to accept donating tooth to research.

A considerable number, $60.8 \%$, of participants in this study would like to learn about the result of the research conducted on their donated tooth. In a study done on French patients, all subjects reported that they would not ask for the result of the research conducted on their teeth. ${ }^{13}$ This is different from the current study and could be related to different sociocultural aspects in Jordan's society.

Current results show that the educational level of BSc or postgraduate degrees was associated with more likelihood

Table 2 Patients' beliefs about the ownership of the donated tooth to research

\begin{tabular}{|c|c|c|}
\hline Factor & Choices & n (\%) \\
\hline What does your tooth mean to you? & $\begin{array}{l}\text { It is a part of me } \\
\text { It has no meaning (indifferent) }\end{array}$ & $\begin{array}{l}269(53.8) \\
232(46.4)\end{array}$ \\
\hline What do you wish to do with your tooth after being extracted? & $\begin{array}{l}\text { I prefer to keep it with me } \\
\text { I prefer to leave it or throw it away } \\
\text { I prefer to donate it to research }\end{array}$ & $\begin{array}{l}31(6.2) \\
175(35) \\
314(62.8)\end{array}$ \\
\hline $\begin{array}{l}\text { If you give your tooth to research, would you think it belongs } \\
\text { to you or to the researcher? }\end{array}$ & $\begin{array}{l}\text { I think it belongs to me always } \\
\text { I think it belongs to the researcher } \\
\text { Not sure }\end{array}$ & $\begin{array}{l}250(50) \\
95(19) \\
155(31)\end{array}$ \\
\hline
\end{tabular}


Table 3 Beliefs toward tooth donation to research

\begin{tabular}{|c|c|c|}
\hline Beliefs & Choices & n (\%) \\
\hline Do you agree to use your extracted tooth in research? & $\begin{array}{l}\text { Yes } \\
\text { No }\end{array}$ & $\begin{array}{l}424(84.8) \\
79(15.8)\end{array}$ \\
\hline How do you evaluate your knowledge of stem cells? & $\begin{array}{l}\text { Excellent } \\
\text { Poor } \\
\text { None }\end{array}$ & $\begin{array}{l}151(30.2) \\
189(37.8) \\
160(32)\end{array}$ \\
\hline Do you agree to use your tooth on stem cell research? & $\begin{array}{l}\text { Yes } \\
\text { No } \\
\text { Not sure }\end{array}$ & $\begin{array}{l}310(61.9) \\
7(1.4) \\
139(27.7)\end{array}$ \\
\hline $\begin{array}{l}\text { Would you like to know the research type that will be done } \\
\text { on your extracted tooth? }\end{array}$ & $\begin{array}{l}\text { Yes } \\
\text { No } \\
\text { Not sure }\end{array}$ & $\begin{array}{l}268(53.6) \\
142(28.4) \\
95(19)\end{array}$ \\
\hline $\begin{array}{l}\text { Do you think you need to sign a consent form before the } \\
\text { donation of your tooth to research? } \\
\text { If yes, when would you like to sign the consent form? }\end{array}$ & $\begin{array}{l}\text { Yes } \\
\text { No } \\
\text { Not sure } \\
\text { At consultation visit, before extraction } \\
\text { At surgery appointment, before extraction } \\
\text { At surgery appointment, after extraction }\end{array}$ & $\begin{array}{l}213(42.6) \\
24 \mid(48.2) \\
46(9.2) \\
142(66.5) \\
28(13.2) \\
43(20.2)\end{array}$ \\
\hline $\begin{array}{l}\text { Would you like to know the result of research on your tooth? } \\
\text { If yes, how do you prefer to be informed? }\end{array}$ & $\begin{array}{l}\text { Yes } \\
\text { No } \\
\text { Not sure } \\
\text { Phone call } \\
\text { E-mail } \\
\text { Letter mail }\end{array}$ & $\begin{array}{l}304(60.8) \\
142(28.4) \\
54(10.8) \\
185(60.8) \\
89(29.2) \\
30(9.8)\end{array}$ \\
\hline
\end{tabular}

Table 4 Participants' attitudes toward tooth donation

\begin{tabular}{|l|l|l|}
\hline Factors & Choices & $\mathbf{n}(\%)$ \\
\hline $\begin{array}{l}\text { Are you worried about extracting your tooth for research purposes } \\
\text { rather than medical purposes? }\end{array}$ & Yes & $307(6 I .4)$ \\
& No & $128(25.6)$ \\
$65(13)$
\end{tabular}

to accept tooth donation. Other demographic variables, including age, gender, income, and place of living, were not significant. Higher educational level is likely to be associated with more knowledge about the importance of donation for research, which leads to more favorable attitude toward donation of an organ. ${ }^{14}$

A considerable percentage of participants refused to donate their teeth to research. This was in line with half of the participants having a sense of ownership toward their extracted tooth. This could be related to the fact that the majority of participants in the current study never participated in any previous research, which reflects the limited research culture in the studied population. For example, perceived knowledge about stem cell research was limited to one-third of the participants. This is in accordance with previous study conducted on public at USA. ${ }^{15}$ Moreover, a previous study reported that the contribution of health care providers in educating public about organ donation was "none" or "little". ${ }^{16}$ Thus, institutional education and local mass media are necessary to have the public more aware about tissue/organ donation, not only in Jordan but also globally.

In the current study, almost half of the participants wished to be informed about the type of scientific research that will be carried out on their teeth after donation. This is in accordance with the previous report. ${ }^{13}$ Phone calls regarding the result of research on tooth were the preferred approach of contact for most participants in the current study. In a study done in Western European population, none preferred to be contacted by phone. Instead, e-mail was the preferred way of communication. ${ }^{13}$ This difference in preference is likely to be due to social difference among studied populations, where phone calls, rather than e-mails, are generally the preferred method of contact in developing countries. 
Table 5 Association of extracted tooth donation with demographic variables

\begin{tabular}{|l|l|l|l|}
\hline \multirow{2}{*}{$\begin{array}{l}\text { Demographic } \\
\text { variables }\end{array}$} & \multicolumn{3}{|l|}{ Willingness to donate extracted } \\
tooth & No & P-value \\
\cline { 2 - 4 } & Yes & No & 0.137 \\
\hline Age (years) & $84(16.8 \%)$ & $22(4.4 \%)$ & \\
$21-30$ & $193(38.7 \%)$ & $33(6.6 \%)$ & \\
$>30$ & $147(29.5 \%)$ & $20(4.0 \%)$ & \\
\hline Gender & & & 0.089 \\
Male & $117(23.4 \%)$ & $27(5.4 \%)$ & \\
Female & $308(61.6 \%)$ & $48(9.6 \%)$ & \\
\hline Place of living & & & 0.380 \\
City & $266(53.2 \%)$ & $45(9 \%)$ & \\
Village & $159(31.8 \%)$ & $30(6.0 \%)$ & \\
\hline Educational level & & & 0.006 \\
Less than high school & $28(5.6 \%)$ & $8(1.6 \%)$ & \\
High school & $56(11.2 \%)$ & $21(4.2 \%)$ & \\
Diploma & $31(6.2 \%)$ & $3(6 \%)$ & \\
BSc & $284(56.8 \%)$ & $41(8.2 \%)$ & \\
Postgraduate & $26(5.2 \%)$ & $2(0.4 \%)$ & \\
\hline Monthly income (US\$) & & & 0.455 \\
Less than $\$ 1,000$ & $332(66.4 \%)$ & $63(12.6 \%)$ & \\
\$I,000-\$2,000 & $69(13.8 \%)$ & $8(1.6 \%)$ & \\
More than $\$ 2,000$ & $24(4.8 \%)$ & $4(0.8 \%)$ & \\
\hline
\end{tabular}

The use of extracted tooth in research is directed by numerous laws and regulations, and how and when to obtain meaningful informed consent from patients are essential for the researchers. In this study, about half of the participants were not willing to sign a consent form to donate their tooth upon extraction. These findings are comparable with those conducted in nearby countries (eg, Saudi Arabia), where more than half of the rural respondents and more than $40 \%$ of the respondents living in the urban areas were not willing to donate organs and the majority were not willing to sign the donation card. ${ }^{16}$ This could be related to misunderstanding among participants of the rationale of the consent form, which reflects the concept of autonomy and decisional auto-determination of the patient of tooth donation. Thus, in Jordan and its regions, educational programs are demanded to enhance the awareness and attitudes of the population on organ donation.

This study showed that $20 \%$ of the patients preferred to sign the consent at surgery visit after extraction. This could be associated with an impaired understanding of informed consent information in older subjects and those with less formal education. This agrees with previous studies from other countries that argued on effective approaches to increase the understanding of informed consent information which should be considered when designing materials, forms, policies, and procedures for obtaining informed consent. ${ }^{17}$
A considerable percentage (41.6\%) of participants in this study were concerned to extract their tooth for research purposes rather than medical purposes. However, in a study conducted on Western Europeans, none of the participants considered the issue that their tooth to be extracted for research purposes rather than medical reasons. ${ }^{13}$ This could reflect an impaired trust among some participants toward dentists involved in studies on extracted tooth.

In this study, the majority of participants $77.6 \%$ preferred to be asked about tooth donation by the dentist rather than any other member of the research team or a member of the health care team. This could be related to patient-dentist relationship; dentists can be familiarized with their patients, and thus patients can feel more comfortable being asked by a dentist and a dentist can educate them about their conditions and ask them about the possibility of tooth donation. In agreement, a previous study from Europe reported that all participants prefer to be informed by the dentist about tooth donation for research. ${ }^{13}$ Thus, in Jordan and other countries, to enhance teeth donation for research among participants, it is better that the patients are approached by the dentists and not by assistants or technicians.

\section{Conclusion}

The majority of Jordanian patients preferred to donate their extracted tooth to research. This was associated with educational level, where participants with BSc or postgraduate degrees were more likely to accept donating tooth to research. Educational programs are demanded to enhance the awareness and attitudes of the patients on the ownership of extracted teeth, consent process, and donation of teeth. The study was conducted on Jordanian population as an example of the Arabic population. More studies from the region are required to confirm the current findings.

\section{Acknowledgment}

The authors would like to thank the Fogarty International Center of the US National Institutes of Health (grant number: 5R25TW010026-02).

\section{Disclosure}

The authors report no conflicts of interest in this work.

\section{References}

1. Bottino MC, Pankajakshan D, Nör JE. Advanced Scaffolds for Dental Pulp and Periodontal Regeneration. Dent Clin North Am. 2017;61(4):689-711.

2. Mortada I, Mortada R, Al Bazzal M. Dental pulp stem cells and the management of neurological diseases: An update. J Neurosci Res. 2018;96(2):265-272.

3. Macrin D, Joseph JP, Pillai AA, Devi A. Eminent Sources of Adult Mesenchymal Stem Cells and Their Therapeutic Imminence. Stem Cell Rev. 2017;13(6):741-756. 
4. D'Aquino R, de Rosa A, Laino G, et al. Human dental pulp stem cells: from biology to clinical applications. J Exp Zool B Mol Dev Evol. 2009;312B(5):408-415.

5. Nam H,Lee G. Identification of novel epithelial stem cell-like cells in human deciduous dental pulp. Biochem Biophys Res Commun. 2009;386(1): 135-139.

6. Seo BM, Miura M, Sonoyama W, Coppe C, Stanyon R, Shi S. Recovery of stem cells from cryopreserved periodontal ligament. J Dent Res. 2005;84(10):907-912.

7. Handa K, Saito M, Tsunoda A, et al. Progenitor cells from dental follicle are able to form cementum matrix in vivo. Connect Tissue Res. 2002;43(2-3):406-408.

8. Handa K, Saito M, Yamauchi M, et al. Cementum matrix formation in vivo by cultured dental follicle cells. Bone. 2002;31(5):606-611.

9. Kerkis I, Caplan AI. Stem cells in dental pulp of deciduous teeth. Tissue Eng Part B Rev. 2012;18(2):129-138.

10. Ismail A. Stem cell research and ethics: an update. Oman Med J. 2015;30(1):1-2.
11. Al-Hayani FA. Muslim perspectives on stem cell research and cloning. J Relig Sci. 2008;43(4):783-795.

12. Kadam RA. Informed consent process: A step further towards making it meaningful! Perspect Clin Res. 2017;8(3):107-112.

13. Le Breton A, Chaussain C, Herve C, Pirnay P. Thoughts on donation of a tooth to science, in the course of dental care. J Forensic Odontostomatol. 2015;33(1):27-37.

14. Sander SL, Miller BK. Public knowledge and attitudes regarding organ and tissue donation: an analysis of the northwest Ohio community. Patient Educ Couns. 2005;58(2):154-163.

15. Nisbet MC. Public Opinion About Stem Cell Research and Human Cloning. Public Opin Q. 2004;68(1):131-154.

16. Alghanim SA. Knowledge and attitudes toward organ donation: a community-based study comparing rural and urban populations. Saudi J Kidney Dis Transpl. 2010;21(1):23-30.

17. Sugarman J, McCrory DC, Hubal RC. Getting meaningful informed consent from older adults: a structured literature review of empirical research. J Am Geriatr Soc. 1998;46(4):517-524.
Clinical, Cosmetic and Investigational Dentistry

\section{Publish your work in this journal}

Clinical, Cosmetic and Investigational Dentistry is an international, peer-reviewed, open access, online journal focusing on the latest clinical and experimental research in dentistry with specific emphasis on cosmetic interventions. Innovative developments in dental materials, techniques and devices that improve outcomes and patient satisfac-
Dovepress

tion and preference will be highlighted. The manuscript management system is completely online and includes a very quick and fair peerreview system, which is all easy to use. Visit http://www.dovepress. $\mathrm{com} /$ testimonials.php to read real quotes from published authors. 